\title{
Twenty years of progress: GIScience in 2010
}

\author{
Michael F. Goodchild \\ Center for Spatial Studies and Department of Geography \\ University of California, Santa Barbara, CA 93106-4060, USA
}

July 27,2010

\begin{abstract}
It is 20 years since the term "geographic information science" was suggested to encompass the set of fundamental research issues that surround GIS. Two decades of GIScience have produced a range of accomplishments, in an expanding literature of research results as well as in the infrastructure of research. Several themes are suggested for future research, based both on gaps in what has been accomplished thus far, and on technology trends that will themselves raise research questions.
\end{abstract}

Keywords: geographic information science

\section{Introduction}

2010 marks the $20^{\text {th }}$ anniversary of the coining of the term "geographic information science," and seems an appropriate opportunity to reflect and review. What progress has been made, what have been the major accomplishments of the field, and what discoveries have been made about the domain of geographic information? Another motivation comes from the $20^{\text {th }}$ anniversary of the funding of the US National Center for Geographic Information and Analysis by the National Science Foundation, which was celebrated at an International Symposium on Geographic Information Science, with an emphasis on review and assessment, in Santa Barbara in December 2008 (ncgia.ucsb.edu/projects / isgis / ).

Any effort to reflect, and to review the vast range of accomplishments of the past 20 years, is inevitably subjective to some degree, reflecting the personal opinions of the author, though comparatively objective sources can be found in the publications and citations of the field, and in the institutions that have emerged. With that in mind, this paper is intended more as a stimulus to others to reflect, and does not pretend to be entirely objective. 
The paper is structured in three sections. The first major section describes the beginnings of GIScience, early definitions of the field and efforts to define a research agenda, and the debates and controversies that inevitably followed. The second section reviews accomplishments, first and primarily from the perspective of achievements in research, but also through a discussion of institutional developments and broader impacts. The third and last major section looks to the future, and presents a few thoughts about the world of geographic information systems and technologies that is likely to emerge in the next ten years. In addition to its focus on persistent, general, and fundamental theory, the field of GIScience has always been driven to some degree by technology, so future developments will need to be examined from three perspectives: first, what research will be needed to ensure that new developments are feasible; second, what research will new technologies stimulate; and third, what issues of a social or ethical nature will new technologies raise, and how should the research community respond?

\section{Beginnings}

\subsection{GIS: Tool or science?}

It is easy to advance a rigorous definition of geographic information: to qualify, a fact must link some property to a location on or near the Earth's surface, and possibly to a point in time or a time interval; geographic information is simply a collection of such facts. But the notion that there might be fundamental issues associated with geographic information, and that these might be studied in a scientific manner, arose only sporadically and in widely scattered fields. Geodesy, for example, requires a systematic and scientifically based approach to the problem of accurately measuring position on a planet that has a complex, non-spherical shape and a similarly complex gravity field; it is easy, therefore, to make the case for a geodetic science. Cartography also deals with geographic information, but in a manner that combines the scientific with the artistic. Photogrammetry is more likely to be identified as a branch of engineering than as a science, since progress relies on finding solutions to a series of technical problems.

Geography, the discipline that studies the social and environmental phenomena of geographic space, has long struggled with the question of whether it is a science. A movement that began in the 1950s and flourished most notably at the University of Washington argued that geography could indeed be a science, and could address its subject matter with quantitative tools. Bunge's Theoretical Geography $|6|$ is one of the most persuasive and compelling statements of the argument. I summarized it in a 2008 essay in a collection of key texts in human geography [30| as:

"that geography is a science; that every science is defined by its domain of knowledge, which for geography is the Earth as the home of humanity; that every science has both a factual or empirical side and a theoretical side; and that 'there are many books on geographic facts and none on theory' [6, p. x]."

Geographic information systems (GIS), a coin termed in the 1960s, had evolved by the late 1980s into a widely adopted software application. The scientific community had been involved from the start in solving the technical problems of building a GIS, including the design of data structures [46] and algorithms for executing simple operations such as

www.josis.org 
topological overlay. But the notion that there might be a science of geographic information took longer to take root [55], and in some quarters the debate continues today.

The first indication that there might be fundamental issues associated with GIS came in the mid 1980s, when Ronald Abler and others began to advocate the establishment of a national center in the US with funding from the National Science Foundation. The solicitation that appeared in 1987, following extensive discussion with the research community, included five potential research areas: spatial analysis and spatial statistics; spatial relationships and database structures; artificial intelligence and expert systems; visualization; and social, economic, and institutional issues [1 43]. The five overlapped the domains of many traditional disciplines, including geography, statistics, computer science, cartography, economics, and political science, but brought them together in a novel multidisciplinary mix.

David Simonett, Principal Investigator of the winning bid for the center from a consortium of the University of California, Santa Barbara, the State University of New York at Buffalo, and the University of Maine, had long been concerned with the lack of theory in his own discipline, remote sensing, and with its overwhelming concern with the development of technology. In his view this left the field vulnerable to attack from more theory-oriented disciplines, and liable to be relegated to second-class status in the academy. How might scientific research about the fundamental issues associated with GIS achieve the kind of status needed for election to the US National Academy of Sciences (NAS), for example, or its equivalent in other countries? There was much discussion of this issue among the center's leadership in its early years.

In the summer of 1990 I was invited to give a keynote address at the $4^{\text {th }}$ International Symposium on Spatial Data Handling, a biennial conference series that had been initiated by Duane Marble and others at the University of Washington in 1984. Arguments over GIS as science were very much on my mind when I wrote the text of the keynote in St Lucia early in 1990 (note the reference to tapes, since data dissemination in this era was still dominated by the $2400 \mathrm{ft}$ reel of half-inch-wide 9 -track magnetic tape):

"What, after all, is spatial data handling? It may describe what we do, but it gives no sense of why we do it. It suggests that spatial data is (sic) somehow difficult to handle, but will that always be so? It suggests a level of detachment from the data themselves, as if the USGS were to send out tapes labeled with the generic warning "handle with difficulty"... We are concerned with much more than the mere handling and processing of data. We are more than the UPS (United Parcel Service) of GIS." |24. p. 3]

Instead, I argued that the community of researchers interested in GIS should see itself as focusing on a spatial information science, and titled the paper accordingly. I laid out a series of fundamental issues which if addressed scientifically might qualify a productive researcher for membership in the NAS.

A second keynote in a similar vein at the Second European GIS Conference in 1991 fleshed out my ideas for a research agenda, and included the first reference to a "geographic information science". It expressed caution over the research agenda, arguing that the posing of a research question did not necessary guarantee useful results:

"Rapid progress was made on algorithms and data structures in the 1970s and 1980s, but many of the hard problems of data modeling, error modeling, 
integration of spatial analysis, and institutional and managerial issues remain. Some of these may be unsolvable-for example, there may simply be no generalities to be discovered (about) the process of adoption of GIS by government agencies, however easy it may be to pose the research question." [25. pp. 342350]

Shortly thereafter Terry Coppock, editor of the new International Journal of Geographical Information Systems (IJGIS), asked me to bring the two keynotes together in a single paper [26]. I titled the paper geographical rather than spatial information science for two reasons. First, I was intrigued by the ambiguity it implied about the decoding of GIS (other authors have since suggested that the $S$ might stand for services or studies as well as systems or science). Second, it seemed to me that there might be general truths to be discovered about geographic space that were not equally true of other spaces, such as the space of the human brain or the genome (see, for example, [29|); but that truths about other spaces might yet provide a creative stimulus to GIScience.

Perhaps the most comprehensive approach to defining GIScience was published by David Mark [39|. He quotes the comparatively succinct definition adopted by the University Consortium for Geographic Information Science: "The development and use of theories, methods, technology, and data for understanding geographic processes, relationships, and patterns." A report to the National Science Foundation following a 1999 workshop [38 | defined GIScience as "The basic research field that seeks to redefine geographic concepts and their use in the context of geographic information systems."

\subsection{The research agenda of GIScience}

The 1992 paper [26 contains a list of eight topics that I thought might be included in the research agenda of this proposed science:

- Data collection and measurement;

- Data capture;

- Spatial statistics;

- Data modeling and theories of spatial data;

- Data structures, algorithms, and processes;

- Display;

- Analytical tools; and

- Institutional, managerial, and ethical issues.

The list is similar to that of the NCGIA research agenda [43], with the omission of the latter's "artificial intelligence and expert systems," an area that seemed to me at the time of writing to be more engineering that science, and which was consistently under-represented in the research of NCGIA.

In 1996 the University Consortium for Geographic Information Science began a longterm effort to develop and regularly update a research agenda for GIScience [52 53] (and see www.ucgis.org). At about the same time, the leaders of NCGIA proposed a simple conceptual framework for the field that allowed its various research topics to be organized in a straightforward way. Each research topic was seen as combining three domains in different proportions: the domain of the computer, the domain of the individual user, and the domain of society. Figure 1 presents this framework as a triangle, with a selection of 
GIScience research topics organized according to the importance to that topic of each of the three domains. The framework became an underlying theme of Project Varenius, NCGIA's late-1990s effort to advance GIScience [33|.

\section{The human}

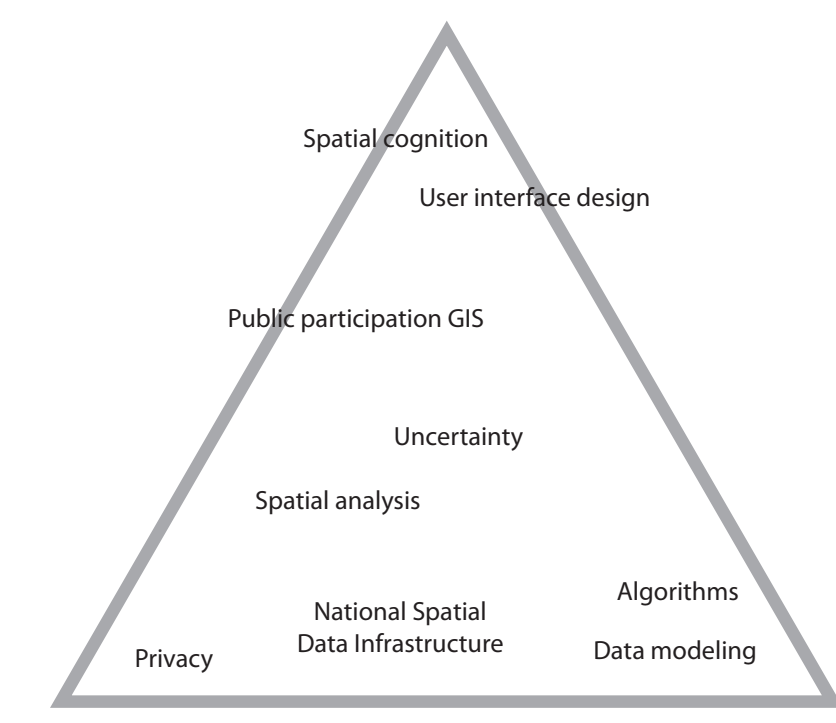

Society

The computer

Figure 1: A conceptual framework for GIScience

All of the various lists that have appeared over the past two decades reflect similar criteria for inclusion. Research topics should address scientific problems that are not yet solved, where there is confidence that general truths remain to be discovered. Problems should be generic, such that results are likely to be general. Problems should be hard, and there should be a reasonable likelihood that scientists in other domains would recognize them as such.

\section{Major accomplishments}

\subsection{Research}

What, then, have been the major accomplishments of the past 20 years of research? As I noted at the outset, any review must of necessity be subjective, but this section begins with a summary of the responses of three participants at the 2008 NCGIA-sponsored International Symposium on Geographic Information Science when selected individuals among the 49 participants were asked to identify the ten most important discoveries of GIScience to date. The question clearly implies an empirical view of the discipline: though advances in theory might be legitimately termed discoveries, it is advances in our understanding of the geographic world itself, more than the development of new 
technologies, that would most obviously qualify. The second subsection examines two more objective approaches to the question based on analysis of citations. Finally the section ends with my own assessment, which is inevitably biased by the directions of my own research.

\subsubsection{Assessments from symposium participants}

Kate Beard of the University of Maine, whose own research has ranged over uncertainty and its visualization, issues of representation and ontology, and geographic information retrieval, started by offering the following metrics for assessing the significance of innovations. An innovation was considered significant based on one or more of the following criteria:

- Widely adopted;

- Led to scientific breakthroughs or benefits;

- Improved data or information understanding; or

- Led to increased ease of use.

Her list, organized by the general categories of data models, statistical analysis, user interfaces, and visualization, included (I have attempted to provide key or representative citations in each case):

- Specification of spatial data types: object and object-relational databases [15.54];

- Specification of spatial relations [16 40|;

- Conditional simulation [18|;

- Local spatial statistics: local autocorrelation, geographically weighted regression [21];

- Common user-interface icons and tools [37|;

- Geographic brushing [42|;

- Standardization: common formats, specifications (the Federal Geographic Data Committee's metadata standard, www.fgdc.gov/metadata/geospatialmetadata-standards; and the work of the Open Geospatial Consortium, www.opengeospatial.org);

- Dorling cartograms [14];

- Generalization as constrained optimization [35|; and

- Google Earth (and the research advances that made it possible, e.g., [45|).

Marc Armstrong of the University of Iowa prefaced his comments by questioning the word discovery, arguing that GIScience was not so much about discovery as about transformation: the transformations undergone by geographic information as it has moved from paper map to machine. He asked whether the greatest discovery of GIScience might not be GIScience itself, as a discipline at the intersection of a number of existing disciplines, with its own domain and agenda. He thought the most important developments of GIScience lay in its focus on abstraction and theory; on topological concepts; on hierarchical data structures [46]; and on ontologies [41|. Key methodological transformations included geocoding, overlay, and other manipulations; and, echoing an item in Beard's list, local spatial analysis.

Sara Fabrikant presented the results of a survey of 16 staff of the GIScience Center at the University of Zürich, including herself. Like Armstrong she was uncomfortable with the

www.josis.org 
term discovery, and rephrased the question to "What are (if any) significant discoveries, contributions, outcomes, and products of the GIScience research community; in other words, do we know something now, or can we do something now, or do we have something now, that we could not have known/done/gotten without the existence of GIScience?" She saw GIScience as an inherently interdisciplinary endeavor in which disciplines operated with a variety of scientific paradigms. She also wondered if discovery might be usefully interpreted in the sense of GIScience enabling the discovery of the world-or its rediscovery [28].

With this reinterpretation of the question, the Zürich list included (with references added in some cases):

- The 9-intersection model [16|;

- Map algebra [50|;

- Geostatistics, and the handling of spatial autocorrelation [8|;

- The geolibrary: geographic information retrieval and spatial search [27|;

- Geography awareness for the masses: geobrowsers, neogeography, volunteered geographic information, location-based services, etc.;

- Geographic visualization [2];

- Agent-based, spatio-temporal simulations and cellular automata [10|;

- Spatial reasoning and cognition: core spatial concepts [22];

- Formalization of spatial concepts: Tobler's First Law [48|, naïve geography [17], scale, vagueness, fields and objects, cartographic design principles; and

- An increased awareness of issues of representation, semantics, social networks, and dynamics.

\subsubsection{Citation analyses}

Peter Fisher conducted a detailed analysis of the first 20 years of IJGIS, looking for papers that might be regarded as classics. He chose 19 articles based on their frequency of citation, limiting them to one per researcher and to advances in basic rather than applied research, and looking for a roughly even dispersion over the 20 years (Table 1). Each paper was then revisited, in many cases by the author(s), and the results were published in a 2006 book [19]. As such, they form another view of the key contributions to GIScience.

Several aspects of the list are striking. First, several topics have already appeared on lists in the previous section, including the Egenhofer and Franzosa analysis of topological relations and the Fotheringham, Brunsdon, and Charlton work on local statistics. Second, three papers report work on uncertainty, yet the topic was absent from all of the previous lists.

André Skupin of San Diego State University presented the results of a citation analysis of GIScience literature at the 2008 symposium. A metric was calculated by counting the number of times any pair of authors were both cited in the same paper in the GIScience literature. The resulting large network of author nodes and co-citation links was then pruned to contain only the most cited authors. That pruned network was laid out in a twodimensional space using a force-directed graph-drawing algorithm (e.g., [13|), such that stronger co-citation links corresponded to closer proximity in the space. Figure 2 shows the results, with the size of each author's name proportional to the number of citations. Three subdomains of GIScience are clearly evident. In the upper right are clustered authors who have worked in the general areas of data modeling and representation, ontology, linguistics, and cognitive issues. In the upper left are researchers whose interests lie in 
1987 Openshaw, Charlton, Wymer, Craft: A Mark I Geographical Analysis Machine for the Automated Analysis of Point Data Sets

1988 Brassel and Weibel: A Review and Conceptual Framework of Automated Map Generalization

1989 Heuvelink, Burrough, and Stein: Propagation of Errors in Spatial Modelling with GIS

1989 Skidmore: A Comparison of Techniques for Calculating Gradient and Aspect from a Gridded Digital Elevation Model

1990 Worboys, Hearnshaw, Maguire: Object-Oriented Data Modelling for Spatial Databases

1991 Egenhofer and Franzosa: Point-Set Topological Spatial Relations

1991 Miller: Modelling Accessibility Using Space-Time Prism Concepts within Geographical Information Systems

1992 Goodchild: Geographical Information Science

1993 Fisher: Algorithm and Implementation Uncertainty in Viewshed Analysis

1995 Raper and Livingstone: Development of a Geomorphological Spatial Model Using ObjectOriented Design

1995 Jankowski: Integrating Geographical Information Systems and Multiple Criteria Decision-Making Methods

1996 Fotheringham, Charlton, Brunsdon: The Geography of Parameter Space: An Investigation of Spatial Non-Stationarity

1996 Frank: Qualitative Spatial Reasoning: Cardinal Directions as an Example

1997 Kiiveri: Assessing, Representing, and Transmitting Positional Uncertainty in Maps

1998 Clarke and Gaydos: Loose-Coupling a Cellular Automaton Model and GIS: Long-Term Urban Growth Prediction for San Francisco and Washington/Baltimore

1998 Bishr: Overcoming the Semantic and Other Barriers to GIS Interoperability

1999 Andrienko and Andrienko: Interactive Maps for Visual Data Exploration

2001 Smith and Mark: Geographical Categories: An Ontological Investigation

2003 Llobera: Extending GIS-Based Visual Analysis: The Concept of Visualscapes

Table 1: The 19 papers selected by Fisher [19| as IJGIS classics.

environmental modeling and topography. Finally the lower center is dominated by research in spatial analysis, with spatial decision support and multicriteria decision-making more to the right and uncertainty and remote sensing more to the left.

\subsubsection{A personal assessment}

Several research accomplishments of the past two decades strike me as particularly noteworthy, while admitting once again that my selection reflects to some degree my own research interests. What follows should be read as one more list of accomplishments, to be added to those already discussed.

First, research in the 1980s had stressed the topic of error, based on the assumption that GIS lay in the scientific tradition of a measurement problem. Positions were measured from maps using digitizing tables, so it was reasonable to ask what accuracies were achievable through this process, and how errors might be modeled. Papers had appeared on the modeling of digitizing error [9], on the propagation of error through GIS operations [36], and on the consequences of error during polygon overlay, otherwise known as the spurious polygon or coastline weave problem. This was the underlying approach reflected in the first NCGIA research initiative, begun with a specialist meeting in late 1988 [23|.

By the late 1990s a fundamental change had occurred, as researchers began to realize

www.josis.org 


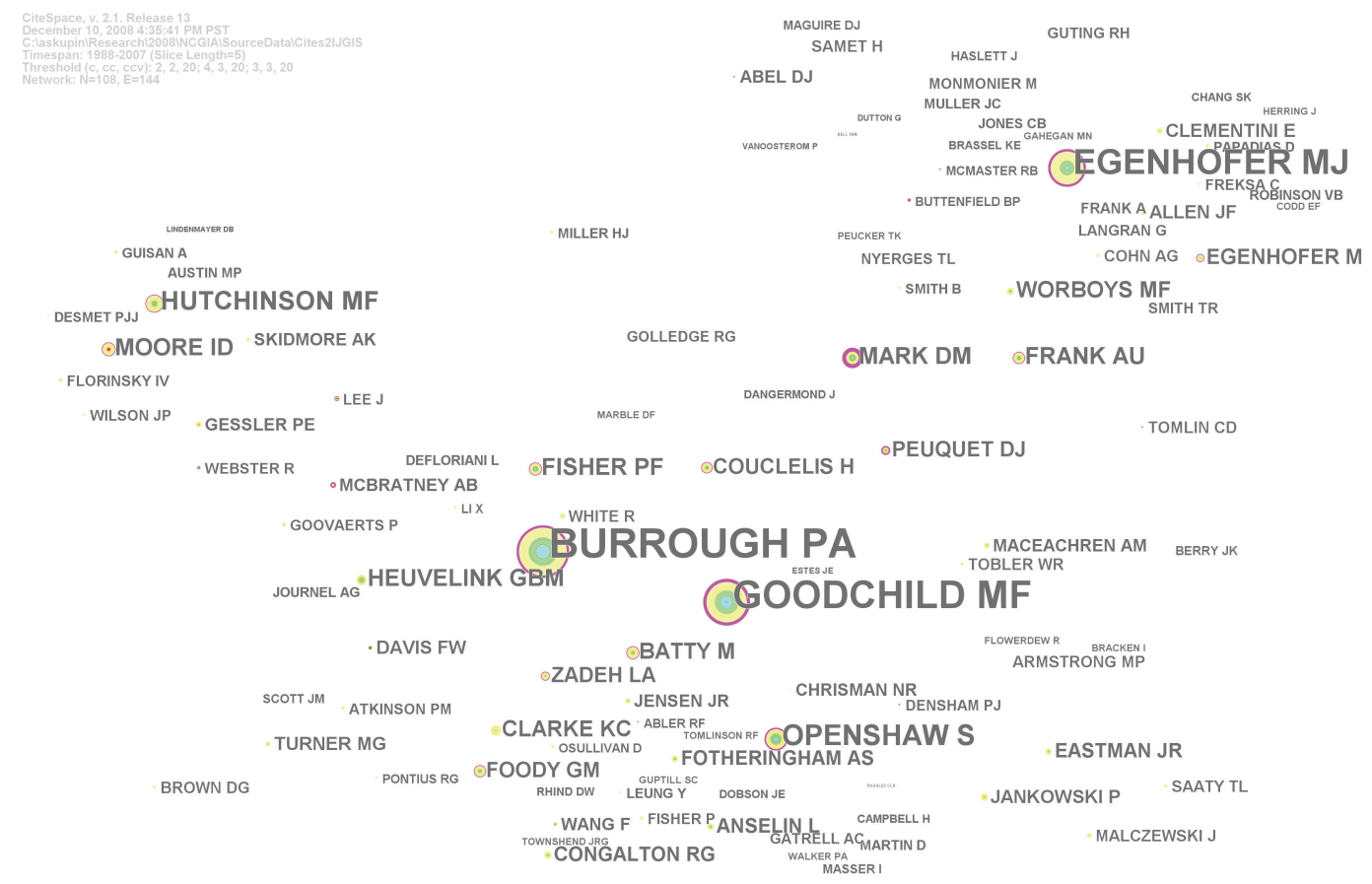

Figure 2: An analysis of the structure of the GIScience literature from citation data (see text for details). Courtesy: André Skupin.

that the problem was not a simple one of scientific measurement. Burrough and Frank [7| recognized that geographic features might have boundaries that were not so much inaccurately recorded as indeterminate, and Fisher and Pathirana [20| and others began a literature on the application of concepts of fuzzy and rough sets to vaguely defined features. This shift from error to uncertainty reflected a deeper transition from thinking about GIScience as concerned with the accurate processing of the contents of maps, to thinking about the entire process of representing and characterizing the geographic world.

Second, finding ways to represent the infinite complexity of the real geographic world in the limited space and binary language of a computing system represents perhaps the greatest research challenge of GIScience. The three decades of GIS development beginning in the mid 1960s had by 1995 produced a vast array of data models and structures in response, many of them proprietary. The problems created by this lack of interoperability led to two intensive efforts: one, led by the Open Geospatial Consortium, to build a set of specifications through consensus among the various branches of the GIS community, and the other, led by the GIScience research community, to find unifying principles that would simplify the options. The early division into raster and vector was underpinned beginning in the early 1990s by conceptualizations of discrete objects and continuous fields (e.g., [11|). These two fundamentally distinct approaches could map to either raster or vector structures, but with very different implications for analysis. The problems of representing data on spatial interactions, which are properties of places taken not one but two at a time, were addressed by Takeyama and Couclelis [49] through their concept of metamaps. Cova 
and Goodchild |12| introduced the object field, a field that maps not to a scalar or vector but to an entire object at every point. Yuan [56| discussed the representation of phenomena that could be conceptualized as discrete objects that move and that carry varying internal structure, such as hurricanes. Finally, Goodchild, Yuan, and Cova [34| showed that all of these options could be reduced to two basic concepts, the geo-atom and the geo-dipole; and that the familiar concepts of GIS representation could be derived from them through various processes of aggregation.

Third, the past two decades have in my view produced a significant clarification of the nature of the geographic world, and the ways in which it influences effective GIS design. Tobler's First Law of Geography had been propounded in 1970, but it was not until the 1990s that the full implications of this disarmingly simple statement-" nearby things are more similar than distant things"- -became apparent [48]. If it were not true, there would be no opportunity to simplify the world through a finite set of regions, or to use spatial interpolation to make estimates of unknown values of fields. In the context of uncertainty, the law implies that relative errors over short distances will almost always be less than absolute errors, a key finding that has implications for the modeling of uncertainty, the design of algorithms to reduce it, and the problem of conflation.

Anselin [3] was perhaps the first to identify a similarly powerful characteristic of the geographic world, that of spatial heterogeneity (or non-stationarity in a statistical sense). Efforts toward a scientific geography, such as those of $|6|$, had always assumed that results would be general, and one of the key arguments in the longstanding debates over these issues had been that principles discovered in one part of the world should also be true in other parts. Idiographic geography had been disparaged as descriptive journalism, yielding nothing universal. But spatial heterogeneity gives this debate a substantially different meaning, since it suggests that general principles about the geographic world will be elusive, especially in the social domain. Numerous methods of local or place-based spatial analysis have been developed over the past two decades, including Anselin's LISA [4| and the geographically weighted regression of Fotheringham, Brunsdon, and Charlton [21], to provide the technical means for investigating spatial heterogeneity.

\subsection{Institutional accomplishments}

While one cannot argue that accomplishments of an institutional nature are as substantive as research accomplishments, nevertheless it is worth noting some of the more significant milestones of the past two decades. First among these is the proliferation, and in some cases renaming, of journals. IJGIS changed Systems to Science in 1997, and Cartography and Geographic Information Systems followed suit in 1999. At the first GIScience conference in Savannah in 2000 the organizers assembled 16 editors of journals dedicated at least in part to publishing work in GIScience, and today the list is substantially longer. Conferences have also proliferated: the GIScience conference is now in its sixth iteration, and specialized conferences such as COSIT, ISSDQ, and others provide fora for exchanging information on progress in subfields of GIScience. The GIScience bookshelf now includes several hundred titles, and the content of GIScience is taught in many programs and curricula.

To return to an earlier theme, one measure of the progress of a discipline is its access to national academies. Waldo Tobler was arguably the first GIScientist elected to the US National Academy of Sciences, and the list of members now includes 7 individuals whose research substantially intersects the domain of GIScience. In the UK, the first geographer 
elected to the Royal Society in recent history, David Rhind, is a GIScientist, and three other elections of GIScientists have followed in the past decade. From any perspective these elections must be taken as a striking recognition of the place of GIScience in the academy in general.

\section{Looking forward: GIScience in the next decade}

One might take various perspectives in asking what lies ahead for GIScience. One might review one or more of the research agendas, and ask where topics have been pursued less vigorously, or with less success. This approach is problematic, however, since progress to date likely already reflects the potential for progress, suggesting that other topics offer diminishing returns. Moreover it is difficult to find areas in the published research agendas where progress has been notably absent. An alternative approach is to look to technology, acknowledging that it has always been one significant factor in driving the GIScience research agenda. In what follows I take a mixed approach, based on part on advances and trends in technology and in part on research topics that remain notably unsolved at this time, and suggest some of the research challenges that might be tackled by GIScience research. The section is organized around five topics, and updated from an earlier discussion [31|.

\subsection{Knowing where everything is, at all times}

The positioning technologies, including satellite-based systems such as GPS and Galileo, along with ground-based systems such as RFID and mobile phone triangulation, have already shown that it is possible to monitor the positions of certain types of objects in real time. Taken as a whole, they suggest that in future it will be possible to know where everything is, at all times. This is already true of mobile phones, certain vehicles, farm animals in some countries, items in the supply chain in certain industries, and construction beams in some new buildings. These technologies pose both technical and social problems for the GIScience research community. How will it be possible to organize, manage, distribute, and use the vast amount of information that will become available? How will it be possible to protect society from the invasions of privacy that such technologies make possible? What new methods of analysis, modeling, and visualization will be required? How should such information be used in time-critical situations such as emergencies, where knowledge of the locations of victims and assets important in response become enormously important?

\subsection{The role of the citizen}

Neogeography [51|, the breaking down of traditional barriers between expert and nonexpert, has already led to widespread awareness of the power of GIS among the general public, and to significant contributions to the supply of geographic data from citizens in what is variously known as volunteered geographic information (VGI), crowdsourced geographic information, and community mapping. Such data can be very valuable in time-critical situations such as emergencies [32], when a dense network of willing and technologically enabled citizens can rapidly acquire useful geographic information. We 
are rapidly approaching a time when the average citizen is both a consumer and producer of geographic information, at least on the empowered side of the digital divide.

This changing role of the citizen presents interesting research challenges. What motivates an individual to volunteer, and what social factors would predict participation? If a citizen is empowered to map anything, what would he or she choose to map? What are the limits to the types of geographic data that can potentially be crowdsourced? What factors determine the quality of crowdsourced information, and what mechanisms and protocols can be used to improve and assure quality?

\subsection{A technology of dynamics}

The technologies discussed in Section 4.1 open the possibility of real-time, continuous monitoring of various aspects of the geographic world, and hence of real-time analysis and modeling. One might imagine a future in which it is possible to know the complete state of the transportation network at all times, for example, or the complete state of an infectious disease outbreak, or the complete state of the Earth environment. Information would be acquired in vast quantities from networks of static, inert sensors distributed in the environment; from sensors carried on moving objects such as vehicles; and from humans themselves using their senses and intelligence to synthesize useful information.

As with the underlying positioning technologies discussed earlier, these scenarios imply a number of research challenges. Over what geographic areas, and at what scale, should such systems be organized: globally, nationally, regionally, or locally? What subset of information can and should be archived for future use? Can the current system of dissemination of data be upgraded to make data available in real time, and what methods of analysis, modeling, visualization, and dissemination of results would be appropriate? Who should have access to such information, and with what constraints?

\subsection{The third, fourth, and fifth dimensions}

Despite much progress in research on the third spatial dimension and time (e.g., |57|), GIS remains a largely two-dimensional technology dominated by the metaphor of the paper map. The third topographic dimension is often handled, but only by imposing the assumption that elevation is a function of location, a solution often termed "2.5D." Numerous applications would follow from the development of a truly 3D GIS that was capable of handling the complex internal structures of mines, buildings, and retail complexes, but progress is stymied by a lack of cost-effective systems for data acquisition that are comparable in efficiency to 2D remote sensing, and by a lack of a cost-effective technology for indoor positioning that is comparable to GPS. GIS remains in large part a technology of the open air. But the issues are more than technological: how, for example, should we conceptualize the key GIS concept of map overlay in 3D? What use cases exist for 3D data and $4 \mathrm{D}$ data, and what ontologies would be appropriate in each case? For example, is a building better modeled as a set of walls in 3D, or as a linear network of nodes (rooms) and links (doorways, hallways) embedded in 3D? What are the primitive elements of a GIS representation of a building, and what is the relationship between architectural design

(e.g., planar walls, rectilinear corners) and GIS representation?

Many researchers (e.g., [5 47]) have discussed a fifth dimension formed by the various attributes that may exist at locations in space-time, and it has been common practice to

www.josis.org 
regard the ability to link data through common geographic location as the primary motivation for GIS. But in reality spatial databases are organized largely as collections of fields distributed over the space-time continuum, or as collections of discrete objects organized by object type, in what might be termed horizontal rather than vertical integration. Thus it is much easier to query a GIS for the value of some property $z(\mathbf{x})$ at all places, than to query for the value of all properties $z$ at one place $\mathbf{x}$. In most software the key function of overlay must be invoked explicitly, and an overlay of $n$ layers might require as many as $n$ - 1 overlay operations. Many mashups merely superimpose one layer on another in a visual spatial join, rather than making a true topological overlay.

There are many reasons for this situation. As noted earlier, the map metaphor, of a GIS as a container of digital representations of paper maps, remains strongly engrained in GIS thinking. All location references are subject to uncertainty, so although we have achieved a high level of interoperability between alternative systems of georeferencing, many spatial joins are at best probabilistic. There is inherent vagueness in the identification of many types of features, and many have indeterminate boundaries. Thus the prime motivation for GIS is likely to present serious research challenges, in the areas of uncertainty, semantics, and database organization, for some time to come.

\subsection{The challenge of education}

Finally, I think it is important to include a discussion of the state of GIS (and GIScience) education in this review and assessment. The technology has become markedly easier to use over the past two decades, and some of the more basic GIS functions are now accessible by the general public. Yet it is easy to find examples (e.g., |44|) where a lack of basic understanding of the concepts behind GIS leads to critical errors. In essence, the education question has changed over the past two decades, from how to educate an elite group of professional experts, to how to provide a basic level of understanding of GIScience principles to everyone. Moreover, even for the expert the ground has shifted, from an earlier emphasis on GIS as a somewhat mechanical process, to the kinds of critical thinking skills needed to manipulate an easy-to-use GIS interface intelligently.

Against this background, we face a sharp contrast between the interfaces of services such as Google Maps, which are easily understood by a child of 10, and the complex and to some degree legacy-defined interfaces of industrial-strength GIS. Despite four decades of research, we have yet to identify the fundamental operations of a GIS in a rigorous, theory-driven way, or to provide the software industry with the principles on which a more intelligent interface might be designed. This lack will become much more critical as we move into an era of service-oriented architectures, when it will be necessary to define functionality in a manner that is sufficiently standardized to be searchable and discoverable.

\section{Conclusion}

Despite the comment made by one keynote speaker at an early GIScience conference that "any field that needs to call itself a science probably isn't," the evidence presented in Section 3 clearly points to substantial accomplishments, and to a recognition by the broader academy that the domain of GIScience defined in Section 2 presents substantial 
research issues that can be addressed using the methods of science. The boundaries between disciplines are less and less relevant in an era when science is more and more collaborative and multidisciplinary, but the domain addressed by GIScience is well-defined and persistent. Thus there seems no danger that GIScience will be absorbed into one of its intersecting disciplines: geography, computer science, or information science. On the other hand a greater interaction with a broader domain of spatial information science seems both logical and desirable.

As I noted at the outset, the purpose of this paper has been to present a review and assessment that is necessarily to some degree personal, with the intent of stimulating more widespread reflection rather than being definitive. Section 4 presented some ideas about the future of GIScience, many of which may turn out to be entirely misdirected; and there are likely many others that will occur to other GIScientists. I have consciously avoided the practice of listing items in a research agenda, and instead tried to anticipate some of the technological developments that will drive research in the coming decade, as well as some notable gaps in our knowledge (Sections 4.4 and 4.5). There are of course many more such gaps, and I hope others will work to identify and publicize them.

\section{Acknowledgments}

Many GIScientists too numerous to mention have contributed immeasurably to the development of the field and to my own research over the past two decades. More specifically, I am grateful to Kate Beard, Marc Armstrong, and Sara Fabrikant for permission to use their lists and for comments on the draft, and to André Skupin for permission to use his citation analysis and figure.

\section{References}

[1] Abler, R. F. The National Science Foundation National Center for Geographic Information and Analysis. International Journal of Geographical Information Systems 1, 4 (1987), 303-326. doi:10.1080/02693798708927819

[2] ANDRIENKO, G., AND ANDRIENKO, N. Interactive maps for visual data exploration. International Journal of Geographical Information Science 13, 4 (1999), 355-374. doi:10.1080/136588199241247.

[3] AnSELIN, L. What is special about spatial data? Tech. Rep. 89-4, National Center for Geographic Information and Analysis, Santa Barbara, CA, 1989.

[4] AnSELin, L. Local indicators of spatial association-LISA. Geographical Analysis 27 (1995), 93-115.

[5] Berry, B. J. L. Approaches to regional analysis: A synthesis. Annals of the Association of American Geographers 54, 2 (1964), 2-11. doi:10.1111/j.1467-8306.1964.tb00469.x

[6] Bunge, W. Theoretical Geography, 2nd ed. No. 1 in Lund Studies in Geography Series C: General and Mathematical Geography. Gleerup, Lund, Sweden, 1966.

www.josis.org 
[7] Burrough, P. A., AND Frank, A. U. Geographic Objects with Indeterminate Boundaries. Taylor and Francis, London, 1996.

[8] Burrough, P. A., And McDonnell, R. Principles of Geographical Information Systems. Oxford, New York, 1998. doi:10.1080/10106048609354060.

[9] Chrisman, N. R., AND YANDELL, B. S. Effects of point error on area calculations: A statistical model. Surveying and Mapping 48 (1988), 241-246.

[10] Clarke, K. C., AND GAYDOS, L. Loose coupling a cellular automaton model and GIS: Long-term growth prediction for San Francisco and Washington/Baltimore. International Journal of Geographical Information Science 12, 7 (1998), 699-714.

[11] Couclelis, H. People manipulate objects but cultivate fields: Beyond the rastervector debate in GIS. In Theories and Methods of Spatial-Temporal Reasoning in Geographic Space, A. U. Frank, I. Campari, and U. Formentini, Eds. Springer, Berlin, 1992, pp. 105138.

[12] Cova, T. J., AND GoOdCHILD, M. F. Extending geographical representation to include fields of spatial objects. International Journal of Geographical Information Science 16, 6 (2002), 509-532. doi:10.1080/13658810210137040.

[13] Di Battista, G., EAdes, P., TAmassia, R., And Tollis, I. G. Graph Drawing: Algorithms for the Visualization of Graphs. Prentice Hall, Englewood Cliffs, NJ, 1999.

[14] Dorling, D. F. L. A New Social Atlas of Britain. Wiley, Chichester, 1995.

[15] Egenhofer, M. J., AND FRAnK, A. U. Object-oriented modeling for GIS. Journal of the Urban and Regional Information Systems Association 4, 2 (1992), 3-19.

[16] Egenhofer, M. J., And Franzosa, R. D. Point-set topological spatial relations. International Journal of Geographical Information Systems 5, 2 (1991), 161-174. doi:10.1080/02693799108927841

[17] Egenhofer, M. J., And Mark, D. M. Naïve geography. In Proc. COSIT 95, Semmering, Austria, A. Frank and W. Kuhn, Eds., vol. 988 of Lecture Notes in Computer Science. Springer, Berlin, 1995, pp. 1-13.

[18] EngLund, E. J. Spatial simulation: Environmental applications. In Environmental Modeling with GIS, M. F. Goodchild, B. O. Parks, and L. T. Steyaert, Eds. Oxford University Press, New York, 1993.

[19] FISHER, P. F., Ed. Classics from IJGIS: Twenty Years of the International Journal of Geographical Information Science. CRC, Hoboken, NJ, 2006. doi:10.1201/ 9781420006377

[20] Fisher, P. F., And Pathirana, S. The evaluation of fuzzy membership of land cover classes in the suburban zone. Remote Sensing of Environment 34 (1990), 121-132. doi:10.1016/0034-4257(90)90103-S.

[21] Fotheringham, A. S., Brunsdon, C., And Charlton, M. Geographically Weighted Regression: The Analysis of Spatially Varying Relationships. Wiley, Hoboken, NJ, 2002. doi:10.1068/a301905 
[22] FRANK, A. U. Qualitative spatial reasoning: Cardinal directions as an example. International Journal of Geographical Information Science 10, 3 (1996), 269-290. doi:10.1080/02693799608902079

[23] Goodchild, M., AND Gopal, S. Accuracy of Spatial Databases. Taylor and Francis, London, 1989.

[24] Goodchild, M. F. Keynote address: Spatial information science. In Fourth International Symposium on Spatial Data Handling (Zurich, July 1990) (1990), vol. 1, pp. 3-14.

[25] Goodchild, M. F. Keynote address-progress on the GIS research agenda. In Second European GIS Conference, Brussels (Utrecht, 1991), EGIS Foundation, pp. 342-350.

[26] Goodchild, M. F. Geographical information science. International Journal of Geographical Information Systems 6, 1 (1992), 31-45. doi:10.1080/ 02693799208901893

[27] Goodchild, M. F. The geolibrary. In Innovations in GIS, S. Carver, Ed., vol. 5. Taylor and Francis, London, 1998, pp. 59-68. doi:10.4324/9780203478776_chapter_FIVE

[28] Goodchild, M. F. Rediscovering the world through GIS: Prospects for a second age of geographical discovery. In GISPlaNET 98, Lisbon (1998).

[29] GoodchILD, M. F. A geographer looks at spatial information theory. In Proc. COSIT 2001, Morro Bay, CA, September, D. R. Montello, Ed., vol. 2205 of Lecture Notes in Computer Science. Springer, Berlin, 2001, pp. 1-13. doi:10.1007/3-540-45424-1_1

[30] Goodchild, M. F. Theoretical geography (1962): William Bunge. In Key Texts in Human Geography, P. Hubbard, R. Kitchin, and G. Valentine, Eds. SAGE, Los Angeles, 2008, pp. 9-16.

[31] Goodchild, M. F. Geographic information systems and science: today and tomorrow. Annals of GIS 15, 1 (2009), 3-9. doi:10.1016/j.proeps.2009.09.160

[32] Goodchild, M. F. Crowdsourcing geographic information for disaster response: a research frontier. International Journal of Digital Earth in press (2010). doi:10.1080/17538941003759255

[33] Goodchild, M. F., Egenhofer, M. J., KeMP, K. K., MARK, D. M., AND Sheppard, E. Introduction to the Varenius project. International Journal of Geographical Information Science 13, 8 (1999), 731-745. doi:10.1080/136588199240996

[34] Goodchild, M. F., YuAN, M., AND Cova, T. J. Towards a general theory of geographic representation in GIS. International Journal of Geographical Information Science 21, 3 (2007), 239-260. doi:10.1080/13658810600965271.

[35] HARRIE, L., AND SARJAKOSKI, T. Simultaneous graphic generalization of vector data sets. Geoinformatica 6, 3 (2002), 233-261. doi:10.1023/ A:1019765902987.

[36] Heuvelink, G., Burrough, P., And Stein, A. Propagation of errors in spatial modeling with GIS. International Journal of Geographical Information Systems 3, 4 (1989), 304-322. doi:10.1080/02693798908941518 
[37] KUHN, W., AND FRANK, A. A formalization of metaphors and image-schemas in user interfaces. In Cognitive and Linguistic Aspects of Geographic Space, D. Mark and A. Frank, Eds. Kluwer, Dordrecht, 1991, pp. 419-434.

[38] MARK, D. M. Geographic information science: Critical issues in an emerging crossdisciplinary research domain. Journal of the Urban and Regional Information Systems Association 12, 1 (2000), 45-54.

[39] MARK, D. M. Geographic information science: Defining the field. In Foundations of Geographic Information Science, M. Duckham, M. F. Goodchild, and M. F. Worboys, Eds. Taylor and Francis, New York, 2003, pp. 1-18. doi:10.1201/9780203009543.ch1

[40] Mark, D. M., AND Frank, A. U. Cognitive and Linguistic Aspects of Geographic Space. Kluwer, Boston, 1991.

[41] Mark, D. M., Hirtle, S. C., Egenhofer, M. J., And Smith, B. Ontological foundations for geographic information science. In A Research Agenda for Geographic Information Science, L. Usery and R. B. McMaster, Eds. CRC Press, Boca Raton, FL, 2005, pp. 335-350. doi:10.1201/9781420038330.ch12

[42] Monmonier, M. Geographic brushing: Enhancing exploratory analysis of the scatterplot matrix. Geographical Analysis 21, 1 (1992), 81-84.

[43] National Center for Geographic information and Analysis (NCGIA). The research plan of the National Center for Geographic Information and Analysis. International Journal of Geographical Information Systems 3, 2 (1989), 117-136.

[44] National ReSEARCH COUNCIL (NRC). Learning to Think Spatially: GIS as a Support System in the K-12 Curriculum. National Academies Press, Washington, DC, 2006.

[45] SAhr, K., White, D., And Kimerling, A. J. Geodesic discrete global grid systems. Cartography and Geographic Information Science 30, 2 (2003), 121-134.

[46] SAmet, H. The Design and Analysis of Spatial Data Structures. Addison-Wesley, Reading, MA, 1990.

[47] Sinton, D. The inherent structure of information as a constraint to analysis: Mapped thematic data as a case study. In Harvard Papers on GIS, G. Dutton, Ed., vol. 7. AddisonWesley, Reading, MA, 1978.

[48] Sul, D. Z. Tobler's first law of geography: A big idea for a small world? Annals of the Association of American Geographers 94 (2004), 269-277. doi:10.1111/j.1467-8306.2004.09402003.x

[49] TAKEYAMA, M., AND COUClelis, H. Map dynamics: Integrating cellular automata and GIS through geo-algebra. International Journal of Geographical Information Science 11 (1997), 73-91. doi:10.1080/136588197242509

[50] Tomlin, C. D. Geographic Information Systems and Cartographic Modeling. Prentice Hall, Englewood Cliffs, NJ, 1990.

[51] TURNER, A. Introduction to Neogeography. OReilly, Sebastopol, CA, 2006. 
[52] UniVERSITY CONSORTIUM FOR GEOGRAPHIC INFORMATION SCIENCE (UCGIS). Research priorities of the University Consortium for Geographic Information Science. Cartography and Geographic Information Systems 23, 3 (1996).

[53] Usery, L., And McMaster, R. B., Eds. A Research Agenda for Geographic Information Science. CRC Press, Boca Raton, 2004. doi:10.1201/9781420038330

[54] Worboys, M. F., Hearnshaw, H. M., and Maguire, D. J. Object-oriented data modelling for spatial databases. International Journal of Geographical Information Systems 4, 4 (1990), 369-383. doi:10.1080/ 02693799008941553

[55] Wright, D. J., Goodchild, M. F., AND Proctor, J. D. Demystifying the persistent ambiguity of GIS as 'tool' versus 'science'. Annals of the Association of American Geographers 87, 2 (1997), 346-362. doi:10.1111/0004-5608.872057.

[56] YUAN, M. Representing complex geographic phenomena with both object- and fieldlike properties. Cartography and Geographic Information Science 28, 2 (2001), 83-96.

[57] YuAn, M., AND HornsbY, K. S., Eds. Computation and Visualization for Understanding Dynamics in Geographic Domains. CRC, Boca Raton, 2008. doi:10.1201/9781420060331 